\title{
Novel biomarker combination improves the diagnosis of serious bacterial infections in Malawian children
}

\author{
Adam D Irwin ${ }^{1 \dagger}$, Fiona Marriage ${ }^{3 \dagger}$, Limangeni A Mankhambo 2,6 , IPD Study Group ${ }^{2}$, Graham Jeffers ${ }^{1}$, \\ Ruwanthi Kolamunnage-Dona ${ }^{4}$, Malcolm Guiver ${ }^{5}$, Brigitte Denis ${ }^{2}$, Elizabeth M Molyneux ${ }^{6}$, Malcolm E Molyneux ${ }^{2}$, \\ Philip J Day ${ }^{3}$ and Enitan D Carrol ${ }^{1,2,6,7^{*}}$
}

\begin{abstract}
Background: High throughput technologies offer insight into disease processes and heightens opportunities for improved diagnostics. Using transcriptomic analyses, we aimed to discover and to evaluate the clinical validity of a combination of reliable and functionally important biomarkers of serious bacterial infection (SBI).

Methods: We identified three previously reported biomarkers of infection (neutrophil gelatinase-associated lipocalin (NGAL), granulysin and resistin) and measured gene expression using quantitative real-time PCR. Protein products related to the three transcripts were measured by immunoassays.

Results: Relative gene expression values of NGAL and resistin were significantly increased, and expression of granulysin significantly decreased in cases compared to controls. Plasma concentrations of NGAL and resistin were significantly increased in children with confirmed SBI compared to children with no detectable bacterial infection (NBI), and to controls (287 versus 128 versus $62 \mathrm{ng} / \mathrm{ml}$ and 195 versus 90 versus $18 \mathrm{ng} / \mathrm{ml}$, respectively, $\mathrm{p}<0.05$ ). Plasma protein concentrations of NGAL and resistin were significantly increased in non-survivors compared to survivors (306 versus 211 and 214 versus $150 \mathrm{ng} / \mathrm{ml}, p=0.02$ ). The respective areas under the curve (AUC) for NGAL, resistin and procalcitonin in predicting $\mathrm{SBI}$ were $0.79,0.80$ and 0.86 , whilst a combination of NGAL, resistin and procalcitonin achieved an AUC of 0.90 .
\end{abstract}

Conclusions: We have demonstrated a unique combination of diagnostic biomarkers of SBI using transcriptomics, and demonstrated translational concordance with the corresponding protein. The addition of NGAL and resistin protein measurement to procalcitonin significantly improved the diagnosis of SBI.

Keywords: Biomarker, Bacterial infection, Transcriptomics, Diagnosis, Protein, Biology, Procalcitonin, Resistin, Neutrophil-associated gelatinase

\section{Background}

Serious bacterial infection (SBI) remains an important contributor to mortality and morbidity in children, particularly in resource-poor countries. Child deaths attributable to invasive Streptococcus pneumoniae and Haemophilus influenzae type b infections are estimated to equal those

\footnotetext{
* Correspondence: edcarrol@liv.ac.uk

${ }^{\dagger}$ Equal contributors

'Department of Women's and Children's Health, University of Liverpool, Liverpool, UK

${ }^{2}$ Malawi-Liverpool-Wellcome Trust Clinical Research Programme, Blantyre, Malawi

Full list of author information is available at the end of the article
}

collectively attributable to HIV, tuberculosis and malaria $[1,2]$. The prompt recognition of SBI in children is challenging clinically, especially so in the context of co-infection with malaria and HIV [3], and is of the utmost importance in ensuring both effective, and rational antibiotic treatment. Diagnostic uncertainty in bacterial sepsis is compensated by the overuse of antibiotics in self-limiting infections, leading to antibiotic resistance.

Biomarkers may be used alone or in combination to allow classification of an individual to a unique group with defined characteristics. Biomarkers which reflect the host response to infection are useful adjuncts to good clinical

\section{Biomed Central}


acumen and improved molecular diagnostic techniques in confirming SBI. Advances in transcriptomics and proteomics have provided basis for biomarker panels unravelled from these technologies, that might be useful in differentiating sepsis-associated inflammation from non-infectious inflammation [4]. An improved understanding of the mechanism of sepsis, and the ability to identify and quantify key mediators involved in its pathophysiology, offers the prospect of reliable diagnostic and prognostic tools. Transcription profiling has been used in other diseases to identify candidate biomarkers [5-7].

Over 170 biomarkers have been related to sepsis, but relatively few have been evaluated as diagnostic markers. A comprehensive review on sepsis biomarkers, concluded that it is unlikely that a single ideal biomarker will ever be found, and that a combination of biomarkers may be more effective [8]. Many of the markers so far investigated are costly and time-consuming to measure. Studies of panels of biomarkers have yielded encouraging results, but none of them have potential to be measured as an affordable pointof- care (POC) test.

The performance of biomarkers is traditionally assessed using receiver operator characteristic (ROC) curves. ROC curves evaluate the discrimination of a test (or combination of tests), but may be insensitive to the addition of a new biomarker, especially if a good biomarker is already included in the model. Net reclassification improvement (NRI) quantifies improvement in the model as a result of adding one or more new biomarkers. This approach has been used in cardiovascular disease [9] and acute lung injury [10] to improve the accuracy of risk prediction.

Resistin is an adipokine first related to insulin resistance in mice [11]. In humans, resistin expression occurs predominantly in macrophages, monocytes and neutrophils $[12,13]$. Circulating resistin levels peak $8-16 \mathrm{~h}$ after the administration of LPS in healthy subjects, mediated by proinflammatory cytokines and NF- $\mathrm{kB}$ [14]. Resistin is significantly elevated in intensive care patients with sepsis [15], and levels correlate with severity of disease [16,17].

Neutrophil gelatinase-associated lipocalin (NGAL) - or lipocalin 2 -has a role in innate immunity through its ability to bind siderophores, required by many bacterial pathogens to scavenge iron from the host [18]. Like resistin, it is highly upregulated by inflammatory stimuli via NF-кB [19]. NGAL is more significantly elevated in sepsis than in the systemic inflammatory response syndrome (SIRS) [20-22]. In a large study of adult patients with suspected sepsis presenting to an emergency department, the optimal 3-marker panel was NGAL, protein C, and interleukin-1 receptor antagonist. The area under the curve for the accuracy of the sepsis score derived from these three biomarkers was 0.80 for severe sepsis, 0.77 for septic shock, and 0.79 for death [23].
Granulysin is an antimicrobial protein co-localised with perforin in the granules of cytotoxic T lymphocytes (CTLs) and natural killer (NK) cells. It has a direct cytotoxic effect on numerous extracellular pathogens, and is postulated to kill intracellular organisms such as Mycobacterium tuberculosis in conjunction with perforin [24]. Granulysin levels correlate inversely with disease activity in $M$. tuberculosis and normalise with treatment [25]. Granulysin is transiently elevated in acute viral infections, and has been suggested as a marker of host cellular immunity [26].

We aimed to identify differentially regulated biomarker transcripts in children with SBI using microarray technology. Three previously identified biomarkers were validated by quantitative real-time PCR in an independent prospective cohort. In order to determine the diagnostic utility of the biomarkers to predict SBI, we measured the proteins of the differentially regulated biomarker genes in plasma samples, to determine if they could reliably predict SBI, or outcome from SBI.

\section{Results and discussion \\ Results}

Of the 377 children included in the study, 282 (74.8\%) presented with meningitis and 95 (25.2\%) presented with pneumonia. The baseline characteristics are summarised in Table 1. There were no significant differences in clinical characteristics (duration of symptoms, previous antibiotics, nutritional status) between children with serious bacterial infection (SBI) and children with signs of severe sepsis but no detectable bacterial infection (NBI), but as expected, the proportion of children presenting with signs of meningitis was significantly higher in the SBI group. The numbers of patients in whom we measured NGAL, resistin, granulysin and procalcitonin are shown in Figure 1, according to STARD guidelines [27].

\section{Relative gene expression}

In the biomarker discovery set using microarray, we studied 12 children with serious bacterial infection (HIV-infected non-survivor $\mathrm{n}=3$, HIV-infected survivor $\mathrm{n}=3$, HIV-uninfected non-survivor $n=3$, HIV-uninfected survivor $n=3$ ), and the control group $(n=3)$. We identified three genes previously reported to be biomarkers of bacterial infection: resistin (RETN), neutrophil gelatinase associated lipocalin (LCN2) and granulysin (GNLY). The following fold changes were observed in controls compared to cases: Resistin -5.88 ( $\mathrm{p}=0.06), \mathrm{NGAL}-4.19,(\mathrm{p}=0.002)$ and granulysin $3.14(\mathrm{p}=0.002)$. These three genes were chosen because $\mathrm{a})$ there was a priori evidence in the literature that they could be markers of infection, b) they had the highest fold changes $(>3,<-3)$, and $c)$ they were all available as commercial ELISAs for measurement of protein in plasma samples. 
Table 1 Characteristics of children with confirmed serious bacterial infection (SBI), those with no detectable bacterial infection (NBI) and controls

\begin{tabular}{|c|c|c|c|c|}
\hline & SBI $(n=280)$ & NBI $(n=97)$ & Controls $(n=15)$ & $p$ value \\
\hline Age (years), median(IQR) & $2.0(0.6-6.9)$ & $2.5(1.0-5.7)$ & $10.0(6.0-13.0)$ & $<0.0005$ \\
\hline Males & $154(55 \%)$ & $61(63 \%)$ & $13 / 21(62 \%)$ & $<0.0005$ \\
\hline Duration of symptoms (days), median(IQR) & $3(2-5)$ & $3(2-5)$ & NR & 0.76 \\
\hline Previous antibiotics (\%) & $123(44 \%)$ & $37(38 \%)$ & NR & 0.32 \\
\hline Meningitis (\%) & $235(84 \%)$ & $47(49 \%)$ & NR & $<0.0005$ \\
\hline Mortality (\%) & $68(24 \%)$ & $15(15 \%)$ & NR & 0.02 \\
\hline HIV-infected (\%) & $145(52 \%)$ & $45(47 \%)$ & $0(0 \%)$ & $<0.0005$ \\
\hline Height for age $Z$ score $<-3(\%)$ & $42 / 272(15 \%)$ & 16/91 (18\%) & ND & 0.63 \\
\hline Weight for height Z score $<-3$ (\%) & $37 / 218(17 \%)$ & $11 / 82(13 \%)$ & ND & 0.45 \\
\hline White cell count (WCC) $\times 10^{9} / /$ median(IQR) & $12.6(7.8-20.0)$ & $13.8(10.0-20.4)$ & ND & 0.09 \\
\hline Neutrophil count $\times 10^{9} / /$ median(IQR) & $10.6(4.6-16.3)$ & $8.9(5.5-15.5)$ & ND & 0.78 \\
\hline
\end{tabular}

Numeric values are median and interquartile range (IQR). (ND = not done, NR= not relevant in a healthy control). Statistical comparison is between three groups,

$\mathrm{SBI}, \mathrm{NBI}$ and controls, using the Kruskal = Wallis test.

In the independent validation set we studied 176 children with serious bacterial infection. Children from the microarray discovery set were excluded. Relative gene expression of resistin and NGAL were significantly increased in cases compared to controls $(\mathrm{p}<0.001)$, and relative gene expression of granulysin was decreased in cases compared to controls. Relative gene expression of NGAL (median $41.2 \mathrm{v}$ 17.7, $\mathrm{p}=0.012)$ granulysin $(0.1 \mathrm{v} 0.07, \mathrm{p}=0.04)$ and resistin (13.7 v 11.0, $\mathrm{p}=0.26)$, was increased in non-survivors compared to survivors (Figure 2).

Plasma concentrations of NGAL, granulysin and resistin in $\mathrm{NBI}, \mathrm{SBI}$ and controls

After adjusting for HIV status, plasma concentrations of NGAL and resistin were significantly increased in children with SBI compared to NBI, compared to controls (287 v 128 v $62 \mathrm{ng} / \mathrm{ml}$ and 195 v 90 v $18 \mathrm{ng} / \mathrm{ml}$, $\mathrm{p}<0.05)$. Plasma concentrations of granulysin were not significantly different between the groups (Figure 3).

Plasma concentrations of NGAL, granulysin and resistin in survivors and non-survivors

After adjusting for HIV status, plasma concentrations of NGAL and resistin were significantly increased in nonsurvivors compared to survivors (306 v $211 \mathrm{ng} / \mathrm{ml}$ and $214 \mathrm{v} 150 \mathrm{ng} / \mathrm{ml}, \mathrm{p}=0.02)$. Plasma concentrations of granulysin were not significantly different between the groups (Figure 3).

\section{Performance of NGAL, granulysin and resistin in predicting SBI}

The performance characteristics (sensitivity, specificity, positive and negative predictive values, and positive and negative likelihood ratios) of NGAL and resistin as

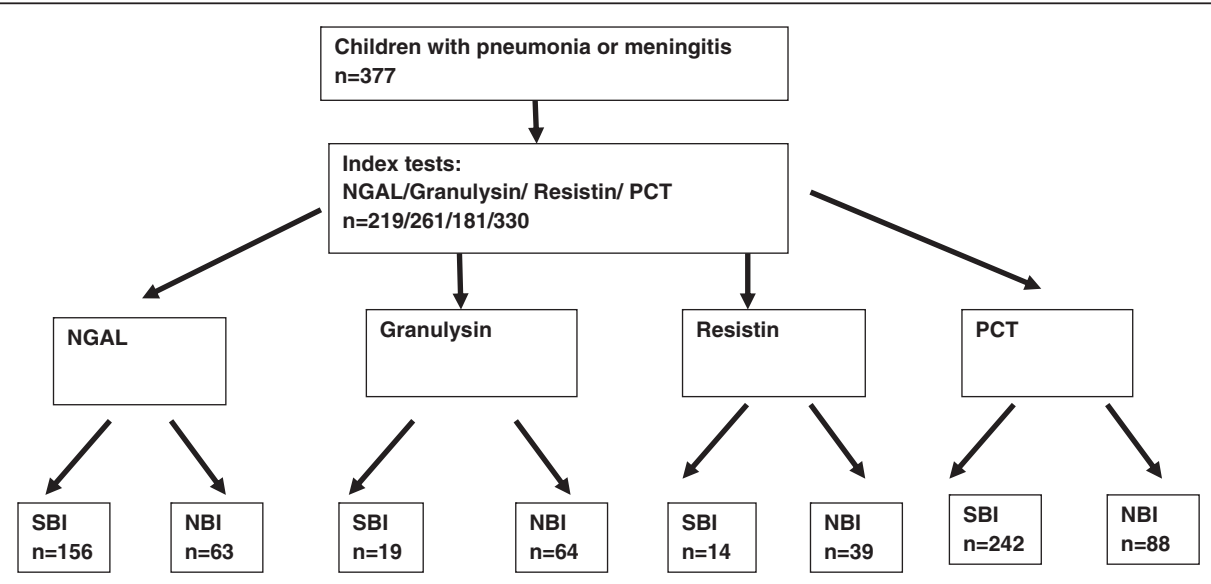

Figure 1 Flow diagram showing the number of patients undergoing index tests and the number of patients with SBI and NBI. The numbers of patients that had each measurement of are shown, according to STARD guidelines [27]. All available samples were tested for all four biomarkers in the following order, procalcitonin, granulysin, NGAL, resistin, as long as there was remaining sample. A total of 181 samples were tested across all four assays. 

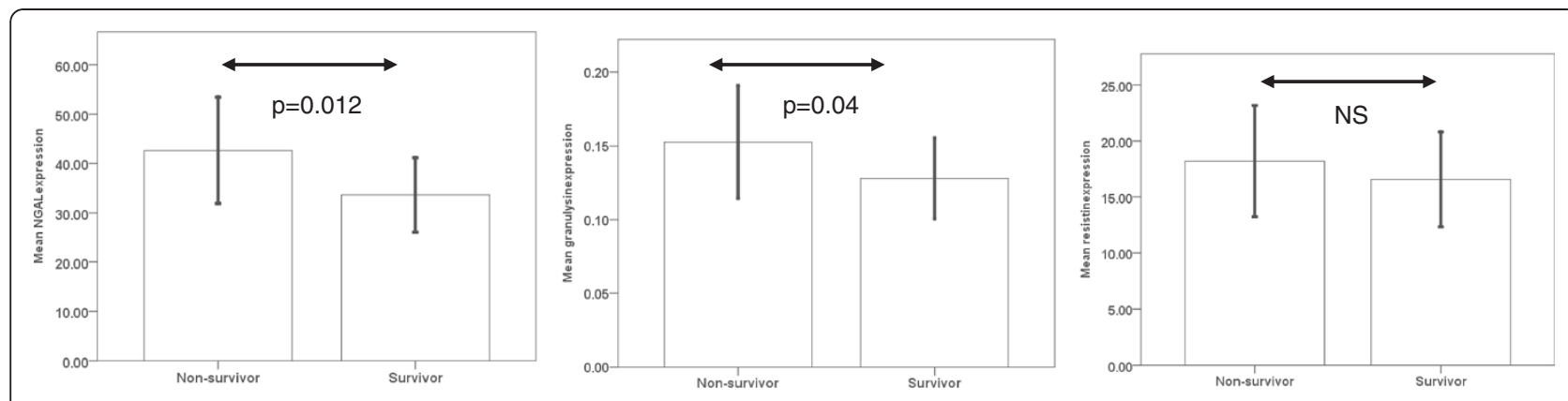

Figure 2 Bar chart showing relative NGAL, granulysin and resistin expression in survivors and non-survivors. A total of 176 samples were analysed using RT PCR. The ++ Ct method was used to calculate normalised data [28]. There was over-expression of NGAL and resistin and under-expression of granulysin in cases compared to controls (data not shown). Relative gene expression of NGAL granulysin and resistin were increased in non-survivors compared to survivors Error bars = mean+/-2SE NS = not significant.

biomarkers of SBI, singly, and in combination with procalcitonin are shown in Table 2. The areas under the curve (AUCs) for NGAL, granulysin and resistin in predicting SBI were NGAL 0.79 (95\% CI 0.73-0.85), granulysin 0.56 (95\% CI 0.48-0.63) and resistin 0.80 (95\% CI 0.72-0.88). Procalcitonin, a previously evaluated biomarker in this cohort [29], had an AUC of 0.86 (0.790.92). The ROC curves of the four biomarkers and the combination of procalcitonin, resistin and NGAL are shown in Figure 4.
Additive value of the biomarkers using net reclassification index

The addition of the biomarkers resistin and NGAL to the currently used biomarker, procalcitonin alone, significantly improved prediction of SBI. Granulysin was dropped from the model because of its poor performance as a single biomarker.

The NRI for the new prediction models are shown in Table 3. Including resistin or NGAL or both resistin and NGAL in the current SBI prediction model (i.e.PCT

\section{a)}
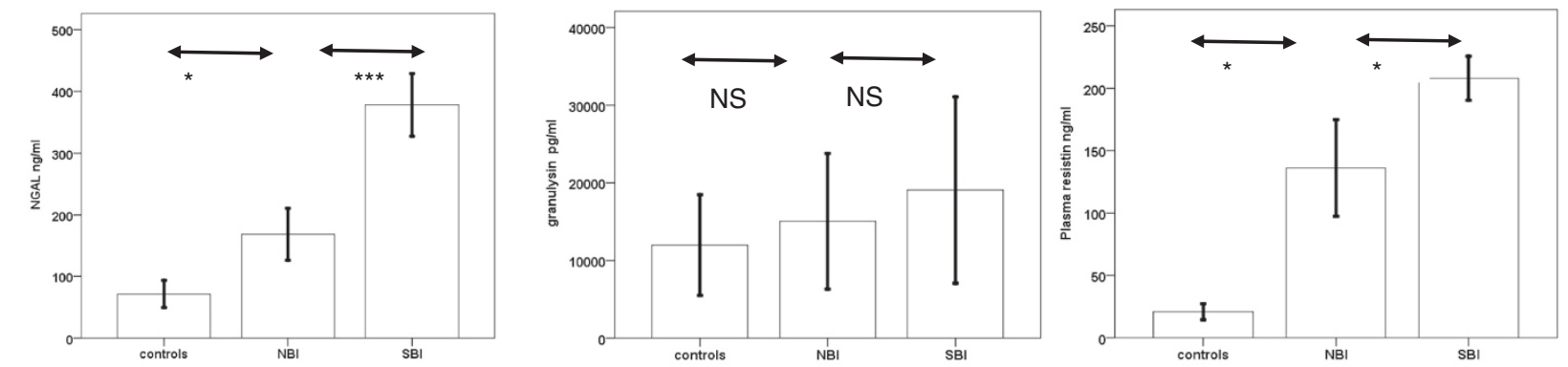

b)
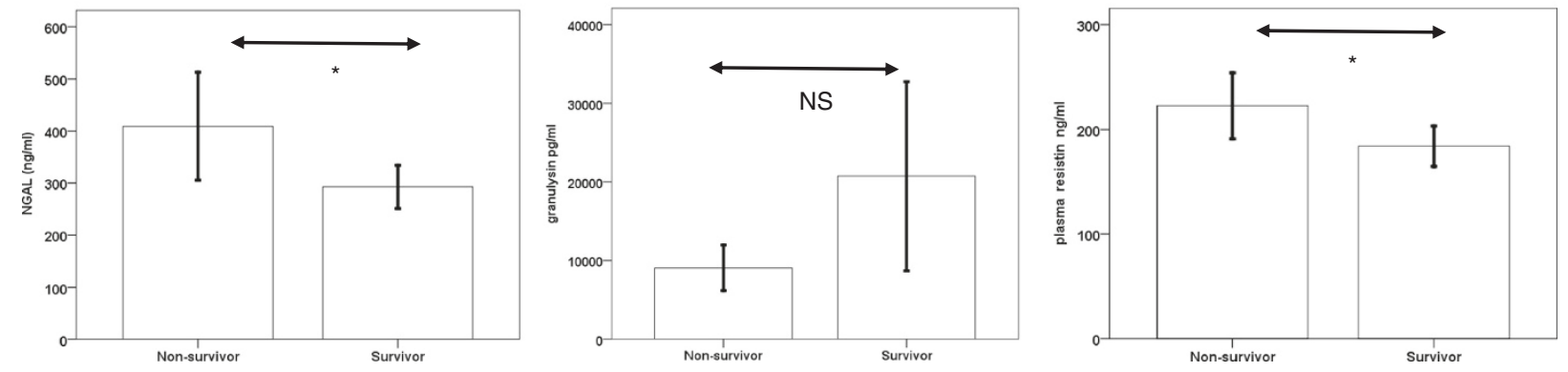

Figure 3 Bar chart showing NGAL, granulysin and resistin concentrations in a) controls, NBI and SBI and b) in survivors and non-survivors. A total of 181 samples were tested across all 4 assays. Plasma concentrations of NGAL and resistin were significantly increased in children with SBI compared to NBI, compared to controls. Plasma concentrations of NGAL and resistin were significantly increased in nonsurvivors compared to survivors. Error bars $=$ mean $+/-2$ SE NS $=$ not significant, ${ }^{* * *}=p<0.0005,{ }^{*}=p<0.05$. 
Table 2 Performance characteristics of NGAL and resistin as biomarkers of SBI, singly, and in combination with procalcitonin

\begin{tabular}{|c|c|c|c|c|c|c|c|}
\hline Marker & Threshold & $\begin{array}{l}\text { Sensitivity } \\
(95 \% \mathrm{Cl})\end{array}$ & $\begin{array}{l}\text { Specificity } \\
(95 \% \mathrm{Cl}) \\
\end{array}$ & $\begin{array}{l}\text { PPV } \\
(95 \% \mathrm{Cl})\end{array}$ & $\begin{array}{l}\text { NPV } \\
(95 \% \mathrm{Cl})\end{array}$ & LR+ & LR- \\
\hline NGAL & 100 & $\begin{array}{l}86.7 \\
(83.2-90.2) \\
\end{array}$ & $\begin{array}{l}50.0 \\
(44.8-55.1) \\
\end{array}$ & $\begin{array}{l}78.7 \\
(74.4-82.9) \\
\end{array}$ & $\begin{array}{l}63.9 \\
(58.9-68.9) \\
\end{array}$ & 1.735 & 0.265 \\
\hline Resistin & 80 & $\begin{array}{l}91.4 \\
(88.4-94.3) \\
\end{array}$ & $\begin{array}{l}51.9 \\
(46.6-57.0) \\
\end{array}$ & $\begin{array}{l}84.1 \\
(80.4-87.9) \\
\end{array}$ & $\begin{array}{l}68.3 \\
(63.5-73.1) \\
\end{array}$ & 1.898 & 0.166 \\
\hline \multicolumn{8}{|c|}{ In combination with Procalcitonin: } \\
\hline PCTNGALResistin & $\begin{array}{l}2 \\
100 \\
80 \\
\end{array}$ & $\begin{array}{l}82.7 \\
(76.6-88.8)\end{array}$ & $\begin{array}{l}76.7 \\
(69.9-83.5)\end{array}$ & $\begin{array}{l}89.6 \\
(84.6-94.5)\end{array}$ & $\begin{array}{l}64.7 \\
(57.0-72.4)\end{array}$ & 3.556 & 0.226 \\
\hline PCTNGALResistin & 18080 & $\begin{array}{l}86.6 \\
(78.8-90.4)\end{array}$ & $\begin{array}{l}72.1 \\
(64.8-79.3)\end{array}$ & $\begin{array}{l}88.0 \\
(82.7-93.2)\end{array}$ & $\begin{array}{l}66.0 \\
(58.3-73.6)\end{array}$ & 3.032 & 0.213 \\
\hline
\end{tabular}

$\mathrm{PPV}=$ positive predictive value, $\mathrm{NPV}=$ negative predictive value, $\mathrm{LR}+=$ likelihood ratio for a positive result, $\mathrm{LR}-=$ likelihood ratio for a negative result.

alone) [29] significantly improved the overall performance. In addition, the incorporation of resistin in the current prediction model results in a $4 \%$ loss of sensitivity (non-significant), but a (significant) 54\% improvement in specificity. The inclusion of NGAL in the current model results in a $1 \%$ gain in sensitivity and a (significant) $56 \%$ gain in specificity. The inclusion of both resistin and NGAL in the current model results in a $14 \%$ gain in sensitivity and a (significant) $67 \%$ gain in specificity.

\section{Discussion}

The diagnosis of SBI is complicated by its variable and non-specific clinical signs and symptoms, and a failure to recognise and promptly treat SBI results in significant morbidity and mortality. The search for accurate biomarkers to influence clinical practice has become paramount for the treatment of sepsis, but to date the search has been disappointing [8]. We have demonstrated concordance between transcript and protein expression for two out of three biomarkers of SBI differentially regulated in microarray screening, validation using quantitative RT-PCR, and measurement of protein concentrations in plasma samples. The discrepancy between RNA expression and protein concentration for granulysin can be explained by a) post-translational modification, b) reduced expression of granulysin in HIVinfected individuals [30] (although after adjusting for HIV the results are the same) and c) delay in granulysin production in HIV-infected individuals due to defective signalling in HIV [31].
Our combination of three biomarkers (resistin, NGAL and procalcitonin) demonstrates good discrimination between SBI and NBI. Adding resistin and NGAL to procalcitonin demonstrates a net reclassification improvement of $81 \%$. To our knowledge, this is the first study to identify a combination of biomarkers for the detection of SBI using a systems biology approach, and to validate diagnostic accuracy. Our data suggest possible inter-relationships between pathways involving resistin, cytotoxic $\mathrm{T}$ cell activity and lipocalin-2, and a significant role for these proteins in the host defence against bacterial infection. The exact mechanisms require further detailed study. Resistin has been shown to attenuate both cytokine production and $\mathrm{T}$ cell activity in a dendritic cells stimulated with lipoteichoic acid [32], and adiponectin (another adipokine) is a negative $\mathrm{T}$ cell regulator [33].

Transcription profiling has been used in other infectious diseases to identify biosignatures of disease groups [5-7]. The use of multiple biomarkers allows the capture of multi-dimensional patterns and pathways, such as those that can occur in complex biological processes like sepsis, and is therefore more robust [34]. Our study is now undergoing further validation in a prospective cohort of febrile children presenting to the emergency department of a large tertiary hospital in England.

In this study, resistin and NGAL provided good discrimination of SBI from NBI (AUC: 0.80 and 0.79 respectively). Individually, neither performed as well as procalcitonin in our previous study [29]. A combination of the three biomarkers performed better (AUC: 0.90)

Table 3 Reclassification improvement in new prediction models versus current PCT alone model

\begin{tabular}{llll}
\hline New model & $\begin{array}{l}\text { Summary NRI } \\
\mathbf{( 9 5 \% ~ C l ) , ~ p - v a l u e ~}\end{array}$ & $\begin{array}{l}\text { NRI for events } \\
(\mathbf{9 5 \%} \text { Cl), p-value }\end{array}$ & $\begin{array}{l}\text { NRI for non-events } \\
\mathbf{( 9 5 \% ~ C l ) , ~ p - v a l u e ~}\end{array}$ \\
\hline PCT + Resistin & $0.50(0.17,0.83), 0.0032$ & $-0.04(-0.22,0.12), 0.6015$ & $0.54(0.26,0.82), 0.0002$ \\
\hline PCT + NGAL & $0.58(0.29,0.86), 0.0001$ & $0.01(-0.15,0.18), 0.8690$ & $0.56(0.32,0.79),<0.0001$ \\
\hline PCT + Resistin + NGAL & $0.81(0.45,1.16),<0.0001$ & $0.14(-0.06,0.33), 0.1700$ & $0.67(0.38,0.97),<0.0001$
\end{tabular}

Event $=\mathrm{SBI}$, non-event $=$ not SBI. 


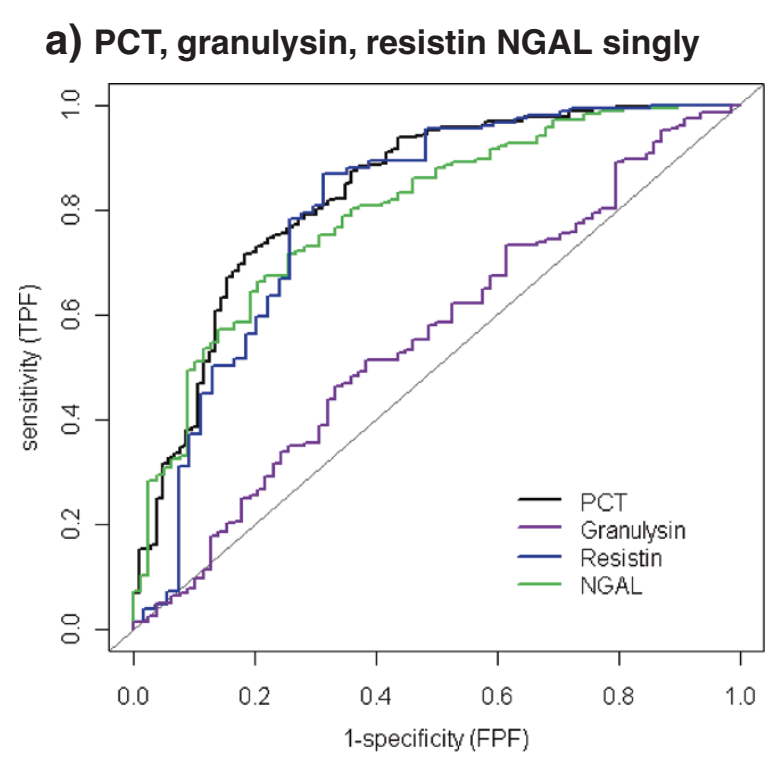

\section{b) Combined PCT, resistin and NGAL}

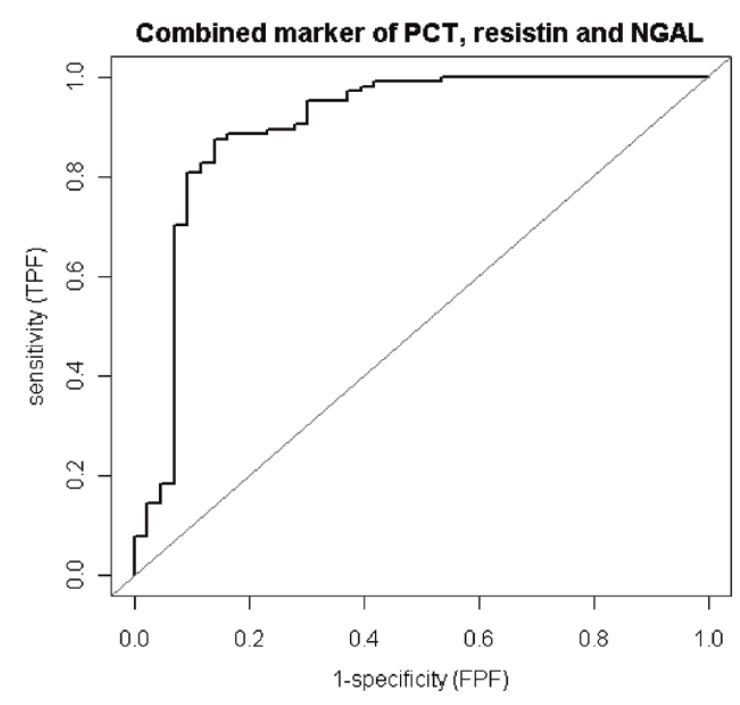

Figure 4 Receiver operator characteristic curves (ROC) of markers of SBI. a) procalcitonin (PCT), granulysin, resistin and NGAL as markers of $\mathrm{SBI}$ and $\mathbf{b}$ ) combination of biomarkers (procalcitonin $(P C T)$, resistin and $N G A L)$ as markers of $S B I$.

than an optimal 3-marker panel (NGAL, protein C, and interleukin-1 receptor antagonist) measured in North American adults presenting to an emergency department with suspected sepsis [23]. As measured by the AUC, our combination of biomarkers resulted in a $10 \%$ improvement in clinical diagnostic accuracy. A more helpful measure however is the NRI. Clinical risk reclassification describes how a new marker or combination of markers may add to predictive models for clinical use, and the NRI can be used to more formally assess clinical utility. An NRI of $81 \%$ is a highly significant improvement in reclassification for clinical management.

Our study exemplifies translational medicine. We have used transcriptomics to develop a better understanding of biomarkers related to the disease process, and to identify potent biosignatures for accurate clinical decision-making. Obstacles to the pipeline for diagnostics have been reported at the "front end" i.e. early stages of discovery and development, and also later, with lack of samples for validating and testing biomarkers [35]. Our study has overcome both these barriers, and is a major step in addressing the pipeline problem in the diagnosis of SBI. If our findings are confirmed prospectively, and if the unique combination of three protein biomarkers could be combined in POC device at low cost, then there is great potential for such a POC device. In primary and secondary care, and in resource-poor settings, POC testing could reduce delays in diagnosis thereby reducing morbidity and mortality, and minimise unnecessary hospital admission and antibiotic prescribing.

\section{Conclusions}

There are currently no rapid diagnostic tests measuring panels of biomarkers of SBI. Our study demonstrates for the first time that a small panel derived from diseaserelated biological processes, is likely to be successful. The addition of resistin and NGAL protein measurement to procalcitonin significantly improves classification. We have identified a unique combination of biomarkers of SBI which could help guide antibiotic management and decisions on referral to hospital. Our data demonstrate exciting improvements in classification, which need to be validated prospectively in a larger cohort.

\section{Materials and methods}

\section{Study setting and population}

Between April 2004 and October 2006, we prospectively enrolled children who presented to the Accident and Emergency Department and the Admissions Unit of Queen Elizabeth Central Hospital, Blantyre, Southern Malawi. The study setting, population and characteristics of study patients have been described previously [29].

The primary outcome measure was bacteriological confirmation of infection (SBI) and the secondary outcome measure was death/survival in hospital. Afebrile children, without malaria parasitaemia, from the same villages as the cases, were used as controls. All controls were HIV-uninfected. Ethical approval for this study was granted from The College of Medicine Research Committee (COMREC), Malawi and The Liverpool School of Tropical Medicine Research Ethics Committee. Parents 
Table 4 Primer sequences and probe numbers for each assay

\begin{tabular}{|c|c|c|c|}
\hline Gene & Forward Primer Sequence & Reverse Primer Sequence & Universal Probe Library \\
\hline$\overline{\text { GNLY }}$ & AGGGTGACCTGTTGACCAAA & CAGCATTGGAAACACTTCTCTG & 17 \\
\hline LCN2 & TCACCTCCGTCCTGTTTAGG & AGGTAACTCGTTAATCCAGGGTAA & 61 \\
\hline RETN & TGCAGGATGAAAGCTCTCTG & CATGGAGCACAGGGTCTTG & 45 \\
\hline ACTB & ATTGGCAATGAGCGGTTC & GGATGCCACAGGACTCCAT & 11 \\
\hline B2M & TTCTGGCCTGGAGGCTATC & TCAGGAAATTTGACTTTCCATTC & 42 \\
\hline GAPDH & AGCCACATCGCTCAGACAC & GCCCAATACGACCAAATCC & 60 \\
\hline GNB2L1 & GCTACTACCCCGCAGTTCC & CAGTITCCACATGATGATGGTC & 55 \\
\hline HMBS & AGCTATGAAGGATGGGCAAC & TTGTATGCTATCTGAGCCGTCTA & 25 \\
\hline HPRT1 & TGACCTTGATTTATTITGCATACC & CGAGCAAGACGTTCAGTCCT & 73 \\
\hline PGK-1 & CTGTGGCTTCTGGCATACCT & CTTGCTGCTTTCAGGACCA & 42 \\
\hline RPL13A & GAGGCCCCTACCACTTCC & TGTGGGGCAGCATACCTC & 28 \\
\hline RPL32 & GAAGTTCCTGGTCCACAACG & GCGATCTCGGCACAGTAAG & 17 \\
\hline SDHA & AGAAGCCCTTTGAGGAGCA & CGATTACGGGTCTATATTCCAGA & 69 \\
\hline TBP & GCTGGCCCATAGTGATCTIT & CTTCACACGCCAAGAAACAGT & 3 \\
\hline YWHAZ & CGTTACTTGGCTGAGGTTGC & TGCTTGTTGTGACTGATCGAC & 9 \\
\hline
\end{tabular}

12 endogenous transcripts (ACTB, B2M, GAPDH, GNB2L1, HMBS, HPRT1, PGK-1, RPL13A, RPL32, SDHA, TBP and YWHAZ) were screened and analysed using the GeNORM algorithm [28].

or guardians gave written informed consent for children to enter the study.

\section{Definitions}

Cases $(n=377)$ Children who presented with signs and symptoms of meningitis or pneumonia, as defined previously [29].

Healthy controls $(\mathbf{n}=15)$ Healthy afebrile children from the same villages as the cases, who had no malarial parasites on blood film. Controls were selected by parents or guardians in the neighbourhood of the index case as part of a larger study investigating genetic susceptibility in IPD [36]. In a small number of children, parental consent was also given to take venous samples for biomarker determination.

Serious bacterial infection (SBI) $(\mathrm{n}=280)$ Children who presented with either bacterial meningitis or bacterial pneumonia, in whom a bacterial pathogen was identified by culture, polysaccharide antigen test or PCR (Streptococcus pneumoniae, Neisseria meningitidis, and Haemophilus influenzae $b$ ).

No detectable bacterial infection (NBI) $(\mathbf{n}=97)$ Children who presented with bacterial meningitis or bacterial pneumonia, but who were negative for any bacteria on culture, polysaccharide antigen test or PCR (S. pneumoniae, N. meningitidis, and H. influenzae $b$ ).

\section{Microbiological methods and malaria diagnosis}

Blood, CSF and lung aspirate culture and PCR were performed using standard microbiological techniques as previously described $[37,38]$. Blood films were examined by microscopy according to best standard practice of district-hospital laboratories in Africa.

\section{RNA extraction and quantification}

Total RNA was extracted from whole blood using an optimised method for the PAXgene ${ }^{\mathrm{TM}}$ blood RNA kit (Qiagen, West Sussex, UK), as previously described [28]. The RNA was concentrated by precipitating overnight at $-20^{\circ} \mathrm{C}$ with $2 \mu \mathrm{l}$ linear acrylamide $(5 \mathrm{mg} / \mathrm{ml})$, (Ambion, Warrington, UK), 0.5 volumes 7.5 M Ammonium acetate (Sigma, Dorset, UK) and 2.5 volumes ice cold $100 \%$ ethanol. The samples were centrifuged at $13,000 \mathrm{~g}, 4^{\circ} \mathrm{C}$ for 30 minutes. The RNA pellet was washed twice with $0.5 \mathrm{ml}$ ice cold $80 \%$ ethanol, each time centrifuging at $4^{\circ} \mathrm{C}$ for 10 minutes at $13,000 \mathrm{~g}$. The pellet was air dried for approximately $5 \mathrm{~min}$ utes and re-suspended in $11 \mu \mathrm{l}$ of nuclease free water.

The total RNA concentration (ng/ $\mu \mathrm{l})$ and ratios $(260 / 280$ and 260/230) were measured using a NanoDrop ND-100 UV-vis spectrophotometer (Labtech International, Ringmer, UK) and the RNA integrity was assessed using the Agilent 2100 Bioanalyser (Agilent Technologies, Edinburgh, UK) pre- and post-concentration.

\section{Reverse transcription for $\mathrm{qPCR}$}

RNA samples were DNAse treated (DNA Free, Ambion, Warrington, UK] to remove any contaminating genomic DNA. RNA $(1 \mu \mathrm{g})$ was reverse transcribed with 
SuperScript II $^{\mathrm{TM}}$ RNase $\mathrm{H}^{-}$Reverse Transcriptase and oligo $(\mathrm{dT})_{12-18}(500 \mu \mathrm{g} / \mathrm{ml})$ following the manufacturer's guidelines ((Invitrogen, Paisley,UK). The cDNA was stored at $-40^{\circ} \mathrm{C}$ until required.

\section{Real-time quantitative PCR measurement of target genes} The Human Universal Probe Library system (Roche, Burgess Hill,UK) employing proprietary locked nucleic acids (LNA) analogues was used for real-time quantitative PCR (qPCR) to measure expression levels in genes of interest. Using the Roche Online Assay Design Centre, specific primers and an associated probe were selected for the reference and target transcripts. Gene expression was determined using real time qPCR on a Roche LightCycler 480. Assays were designed using the Roche Universal ProbeLibrary system. Table 4 shows the primer sequences and the probe number for each assay. Assays were run in triplicate $10 \mu \mathrm{l}$ reactions in 384 well plates. Each well contained $5 \mu \mathrm{l}$ LightCycler 480 Probes Master (2x concentration), $0.1 \mu$ l each primer $(20 \mu \mathrm{M})$, $0.1 \mu \mathrm{l}$ probe $(10 \mu \mathrm{M}), 0.7 \mu \mathrm{l}$ water and $4 \mu \mathrm{l}$ of $\mathrm{cDNA}$ (1:40 dilution). The thermocycling conditions were: $95^{\circ} \mathrm{C}$ for 5 minutes, then 50 cycles of $95^{\circ} \mathrm{C}$ for 10 seconds and $60^{\circ} \mathrm{C}$ for 30 seconds, a final cooling step of $40^{\circ} \mathrm{C}$ for 10 seconds completes the program. To compensate for variations in cell number, RNA isolation, reverse transcription and PCR amplification efficiency, 12 endogenous transcripts (ACTB, B2M, GAPDH, GNB2L1, HMBS, HPRT1, PGK-1, RPL13A, RPL32, SDHA, TBP and YWHAZ) were screened and analysed using the GeNORM algorithm [39], HPRT1, GAPDH and YWHAZ were selected as suitable reference genes. A total of 176 randomly selected samples were analysed using qPCR. The amounts of target genes expressed in a sample are normalized to the average of the three endogenous controls. This is given by $\Delta C_{T}$, where $\Delta C_{T}$ is determined by subtracting the average endogenous gene $C_{T}$ value from the average target gene $C_{T}$ value. $\left[C_{T}\right.$ target gene $-C_{T}$ average (endogenous gene)]. The calculation of $\Delta \Delta C_{T}$ involves subtraction of $\Delta C_{\mathrm{T}}$ value for the controls from the $\Delta C_{T}$ value for the cases $\left[\Delta C_{T}\right.$ target gene (case) $-\Delta C_{T}$ target gene (control) $] .2^{-\Delta \Delta C t}$ is the relative expression of the target gene in cases compared to controls [28].

\section{NGAL, resistin and granulysin measurement by ELISA}

NGAL (R\&D Systems, Abingdon, UK), resistin (Universal Biologicals, Cambridge, UK) and granulysin (ABO Swiss, Xiamen, China) were measured in plasma samples using commercially available sandwich enzyme immunoassays according to the manufacturers' instructions. Assays were performed on plasma samples if there was enough sample for the different assays.

\section{Statistical analysis}

Basic analysis was performed using SPSS for Windows, version 15.0, (Illinois, USA), and ROCR and Hmisc packages in $\mathrm{R}$ (http://www.r-project.org/) were used in summarising the performances of biomarkers and computing the net reclassification improvement (NRI). The data, when plotted, did not follow a normal distribution, and therefore the Mann Whitney Test was used to compare distributions. Receiver operator characteristic (ROC) curves were used to determine the areas under the curve (AUCs) with 95\% confidence intervals for the biomarkers to predict SBI and death. The laboratory assays for bacteriological confirmation and the markers of infection were performed by investigators blinded to the clinical data. The clinicians involved in managing the cases were not involved in performing any of the laboratory assays.

Net reclassification improvement (NRI) [40] was used to measure the additive value of measuring multiple biomarkers and to quantify improvement in performance over procalcitonin alone, which has previously been shown to be the best biomarker of SBI in Malawian children with signs of severe sepsis [29]. The magnitude of NRI is more important than the statistical significance, therefore we reported NRI with confidence intervals, as well as significance values [40].

The study was reported according to STARD guidelines which includes method of recruitment of patients, orders of test execution, and numbers of patients undergoing the tests under evaluation and the numbers of patients with the reference standard [27] (Figure 1).

\section{Competing interests}

All authors state that they do not have any conflicts of interest to declare.

\section{Authors' contributions}

FM conceived and designed experiments, performed laboratory analysis, and helped draft the manuscript. ADI performed statistical analysis, and drafted the manuscript. LAM recruited patients and collected data. IPD Study Group recruited patients and collected data. GJ performed laboratory analysis. RK-D performed statistical analysis and contributed to writing the manuscript. MG performed microbiology analysis and helped draft the manuscript. BD performed microbiology analysis. EMM contributed to writing the manuscript. MEM contributed to writing the manuscript. PJD conceived and designed experiments contributed to writing the manuscript. EDC conceived and designed experiments, performed statistical analysis, and drafted the manuscript. All authors have read and approved the final manuscript.

\section{Acknowledgements}

The IPD (Invasive Pneumococcal Disease) Study Group (Nurses: C Antonio, M Chinamale, L Jere, D Mnapo, V Munthali, F Nyalo, J Simwinga, Clinical Officer: M Kaole, Lab scientist: DL Banda, Field Workers: A Manyika, K Phiri) recruited patients. We are grateful to Dr Stuart Pepper and Dr Mark Wappett for assistance with bioinformatics analysis. The Director of MLW, Professor Robert S Heyderman, provided helpful comments on the manuscript. We thank the children included in this study, and their parents and guardians for giving consent for them to participate in the study. We also extend thanks to the nursing and medical staff, at the Malawi-Liverpool-Wellcome Trust Clinical Research Programme (MLW), Research Ward, for their contribution to this study. 
This work was supported by a Wellcome Trust Career Development Grant [Grant No. 068026] to EDC; National Institute for Health Research grant [RCPG-0309-10053] to EDC provided support for ADI. The Malawi-LiverpoolWellcome Trust Clinical Research Programme is supported by the Wellcome Trust. The funding bodies had no role in collection, analysis or interpretation of data or in writing the manuscript.

\section{Author details}

'Department of Women's and Children's Health, University of Liverpool Liverpool, UK. ${ }^{2}$ Malawi-Liverpool-Wellcome Trust Clinical Research Programme, Blantyre, Malawi. ${ }^{3}$ Centre for Integrated Medical Genomic Research, University of Manchester, Manchester, UK. ${ }^{4}$ Department of Biostatistics, University of Liverpool, Liverpool, UK. ${ }^{5}$ Health Protection Agency North West, Manchester Medical Microbiology Partnership, Manchester, UK. ${ }^{6}$ Department of Paediatrics, University of Malawi College of Medicine, Blantyre, Malawi. ${ }^{7}$ Institute of Child Health, University of Liverpool, Alder Hey Children's NHS Foundation Trust, Eaton Road, Liverpool, L12 2AP, UK.

\section{Received: 6 January 2012 Accepted: 27 March 2012}

Published: 4 May 2012

\section{References}

1. Watt JP, Wolfson LJ, O'Brien KL, Henkle E, Deloria-Knoll M, McCall N, Lee E, Levine OS, Hajjeh R, Mulholland $K$, et al: Burden of disease caused by Haemophilus influenzae type $b$ in children younger than 5 years: global estimates. Lancet 2009, 374(9693):903-911.

2. O'Brien $\mathrm{KL}$, Wolfson LJ, Watt JP, Henkle E, Deloria-Knoll M, McCall N, Lee E, Mulholland K, Levine OS, Cherian T: Burden of disease caused by Streptococcus pneumoniae in children younger than 5 years: global estimates. Lancet 2009, 374(9693):893-902.

3. Nadjm B, Amos B, Mtove G, Ostermann J, Chonya S, Wangai H, Kimera J, Msuya W, Mtei F, Dekker D, et al: WHO guidelines for antimicrobial treatment in children admitted to hospital in an area of intense Plasmodium falciparum transmission: prospective study. BMJ 2010, 340: c1350.

4. Tang BM, McLean AS, Dawes IW, Huang SJ, Lin RC: Gene-expression profiling of peripheral blood mononuclear cells in sepsis. Crit Care Med 2009, 37(3):882-888.

5. Pankla R, Buddhisa S, Berry M, Blankenship DM, Bancroft GJ, Banchereau J, Lertmemongkolchai G, Chaussabel D: Genomic transcriptional profiling identifies a candidate blood biomarker signature for the diagnosis of septicemic melioidosis. Genome Biol 2009, 10(11):R127.

6. Jacobsen M, Repsilber D, Gutschmidt A, Neher A, Feldmann K, Mollenkopf HJ, Ziegler A, Kaufmann SH: Candidate biomarkers for discrimination between infection and disease caused by Mycobacterium tuberculosis. J Mol Med (Berl) 2007, 85(6):613-621.

7. Wong HR, Cvijanovich NZ, Allen GL, Thomas NJ, Freishtat RJ, Anas N, Meye $K$, Checchia PA, Lin R, Shanley TP, et al: Validation of a gene expressionbased subclassification strategy for pediatric septic shock. Crit Care Med 2011, 39(11):2511-2517.

8. Pierrakos C, Vincent JL: Sepsis biomarkers: a review. Crit Care 2010, 14(1): R15.

9. Zethelius B, Berglund L, Sundstrom J, Ingelsson E, Basu S, Larsson A, Venge

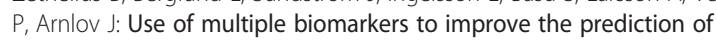
death from cardiovascular causes. N Engl J Med 2008, 358(20):2107-2116.

10. Calfee CS, Ware LB, Glidden DV, Eisner MD, Parsons PE, Thompson BT, Matthay MA: Use of risk reclassification with multiple biomarkers improves mortality prediction in acute lung injury. Crit Care Med 2011, 39 (4):711-717

11. Steppan CM, Bailey ST, Bhat S, Brown EJ, Banerjee RR, Wright CM, Patel HR, Ahima RS, Lazar MA: The hormone resistin links obesity to diabetes. Nature 2001, 409(6818):307-312.

12. Savage DB, Sewter CP, Klenk ES, Segal DG, Vidal-Puig A, Considine RV, O'Rahilly S: Resistin/Fizz3 expression in relation to obesity and peroxisome proliferator-activated receptor-gamma action in humans. Diabetes 2001, 50(10):2199-2202.

13. Johansson L, Linner A, Sunden-Cullberg J, Haggar A, Herwald H, Lore K, Treutiger CJ, Norrby-Teglund A: Neutrophil-derived hyperresistinemia in severe acute streptococcal infections. J Immunol 2009, 183(6):4047-4054.
14. Lehrke M, Reilly MP, Millington SC, lqbal N, Rader DJ, Lazar MA: An inflammatory cascade leading to hyperresistinemia in humans. PLoS Med 2004, 1(2):e45

15. Koch A, Gressner OA, Sanson E, Tacke F, Trautwein C: Serum resistin levels in critically ill patients are associated with inflammation, organ dysfunction and metabolism and may predict survival of non-septic patients. Crit Care 2009, 13(3):R95.

16. Sunden-Cullberg J, Nystrom T, Lee ML, Mullins GE, Tokics L, Andersson J, Norrby-Teglund A, Treutiger CJ: Pronounced elevation of resistin correlates with severity of disease in severe sepsis and septic shock. Crit Care Med 2007, 35(6):1536-1542.

17. Kaplan JM, Denenberg A, Monaco M, Nowell M, Wong H, Zingarelli B: Changes in peroxisome proliferator-activated receptor-gamma activity in children with septic shock. Intensive Care Med 2010, 36(1):123-130.

18. Flo TH, Smith KD, Sato S, Rodriguez DJ, Holmes MA, Strong RK, Akira S, Aderem A: Lipocalin 2 mediates an innate immune response to bacterial infection by sequestrating iron. Nature 2004, 432(7019):917-921.

19. Cowland JB, Muta T, Borregaard N: IL-1beta-specific up-regulation of neutrophil gelatinase-associated lipocalin is controlled by lkappaB-zeta. J Immunol 2006, 176(9):5559-5566.

20. Wheeler DS, Devarajan P, Ma Q, Harmon K, Monaco M, Cvijanovich N, Wong HR: Serum neutrophil gelatinase-associated lipocalin (NGAL) as a marker of acute kidney injury in critically ill children with septic shock. Crit Care Med 2008, 36(4):1297-1303.

21. Bagshaw SM, Bennett M, Haase M, Haase-Fielitz A, Egi M, Morimatsu H, D'Amico G, Goldsmith D, Devarajan P, Bellomo R: Plasma and urine neutrophil gelatinase-associated lipocalin in septic versus non-septic acute kidney injury in critical illness. Intensive Care Med 2010, 36(3):452-461.

22. Martensson J, Bell M, Oldner A, Xu S, Venge P, Martling CR: Neutrophil gelatinase-associated lipocalin in adult septic patients with and without acute kidney injury. Intensive Care Med 2010, 36(8):1333-1340.

23. Shapiro NI, Trzeciak S, Hollander JE, Birkhahn R, Otero R, Osborn TM, Moretti E, Nguyen $H B$, Gunnerson KJ, Milzman D, et al: A prospective, multicenter derivation of a biomarker panel to assess risk of organ dysfunction, shock, and death in emergency department patients with suspected sepsis. Crit Care Med 2009, 37(1):96-104.

24. Stenger S, Hanson DA, Teitelbaum R, Dewan P, Niazi KR, Froelich CJ, Ganz T, Thoma-Uszynski S, Melian A, Bogdan C, et al: An antimicrobial activity of cytolytic T cells mediated by granulysin. Science 1998, 282(5386):121-125

25. Di Liberto D, Buccheri S, Caccamo N, Meraviglia S, Romano A, Di Carlo P, Titone L, Dieli F, Krensky AM, Salerno A: Decreased serum granulysin levels in childhood tuberculosis which reverse after therapy. Tuberculosis (Edinb) 2007, 87(4):322-328.

26. Ogawa K, Takamori Y, Suzuki K, Nagasawa M, Takano S, Kasahara Y, Nakamura Y, Kondo S, Sugamura K, Nakamura M, et al: Granulysin in human serum as a marker of cell-mediated immunity. Eur J Immunol 2003, 33(7):1925-1933.

27. Bossuyt PM, Reitsma JB, Bruns DE, Gatsonis CA, Glasziou PP, Irwig LM, Lijmer JG, Moher D, Rennie D, de Vet HC: Towards complete and accurate reporting of studies of diagnostic accuracy: The STARD Initiative. Ann Intern Med 2003, 138(1):40-44.

28. Carrol ED, Salway F, Pepper SD, Saunders E, Mankhambo LA, Ollier WE, Hart CA, Day P: Successful downstream application of the Paxgene Blood RNA system from small blood samples in paediatric patients for quantitative PCR analysis. BMC Immunol 2007, 8:20.

29. Carrol ED, Mankhambo LA, Jeffers G, Parker D, Guiver M, Newland P, Banda DL, Molyneux EM, Heyderman RS, Molyneux ME, et al: The diagnostic and prognostic accuracy of five markers of serious bacterial infection in Malawian children with signs of severe infection. PLoS One 2009, 4(8): e6621.

30. Hogg AE, Bowick GC, Herzog NK, Cloyd MW, Endsley JJ: Induction of granulysin in CD8+ T cells by IL-21 and IL-15 is suppressed by human immunodeficiency virus-1. J Leukoc Biol 2009, 86(5):1191-1203.

31. Zheng CF, Jones GJ, Shi M, Wiseman JC, Marr KJ, Berenger BM, Huston SM, Gill MJ, Krensky AM, Kubes P, et al: Late expression of granulysin by microbicidal CD4+ T cells requires PI3K- and STAT5-dependent expression of IL-2Rbeta that is defective in HIV-infected patients. J Immunol 2008, 180(11):7221-7229.

32. Son YM, Ahn SM, Jang MS, Moon YS, Kim SH, Cho KK, Han SH, Yun CH: Immunomodulatory effect of resistin in human dendritic cells stimulated 
with lipoteichoic acid from Staphylococcus aureus. Biochem Biophys Res Commun 2008, 376(3):599-604

33. Wilk S, Scheibenbogen C, Bauer S, Jenke A, Rother M, Guerreiro M, Kudernatsch R, Goerner N, Poller W, Elligsen-Merkel D, et al: Adiponectin is a negative regulator of antigen-activated T cells. Eur J Immunol 2011, 41(8):2323-2332.

34. Jacobsen M, Mattow J, Repsilber D, Kaufmann SH: Novel strategies to identify biomarkers in tuberculosis. Biol Chem 2008, 389(5):487-495.

35. Phillips KA, Van Bebber S, Issa AM: Diagnostics and biomarker development: priming the pipeline. Nat Rev Drug Discov 2006, 5(6):463469.

36. Payton A, Payne D, Mankhambo LA, Banda DL, Hart CA, Ollier WE, Carrol ED: Nitric oxide synthase $2 \mathrm{~A}$ (NOS2A) polymorphisms are not associated with invasive pneumococcal disease. BMC Med Genet 2009, 10:28.

37. Carrol ED, Guiver M, Nkhoma S, Mankhambo LA, Marsh J, Balmer P, Banda DL, Jeffers G, White SA, Molyneux EM, et al: High pneumococcal DNA loads are associated with mortality in Malawian children with invasive pneumococcal disease. Pediatr Infect Dis J 2007, 26(5):416-422.

38. Carrol ED, Mankhambo LA, Guiver M, Banda DL, Denis B, Dove W, Jeffers $G$, Molyneux EM, Molyneux ME, Hart CA, et al: PCR Improves Diagnostic Yield from Lung Aspiration in Malawian Children with Radiologically Confirmed Pneumonia. PLoS One 2011, 6(6):e21042.

39. Vandesompele J, De Preter K, Pattyn F, Poppe B, Van Roy N, De Paepe A, Speleman F: Accurate normalization of real-time quantitative RT-PCR data by geometric averaging of multiple internal control genes. Genome Biol 2002, 3(7):RESEARCHO034

40. Pencina MJ, D'Agostino RB Sr, Steyerberg EW: Extensions of net reclassification improvement calculations to measure usefulness of new biomarkers. Stat Med 2011, 30(1):11-21.

doi:10.1186/1755-8794-5-13

Cite this article as: Irwin et al: Novel biomarker combination improves the diagnosis of serious bacterial infections in Malawian children. BMC Medical Genomics 2012 5:13.

\section{Submit your next manuscript to BioMed Central and take full advantage of:}

- Convenient online submission

- Thorough peer review

- No space constraints or color figure charges

- Immediate publication on acceptance

- Inclusion in PubMed, CAS, Scopus and Google Scholar

- Research which is freely available for redistribution 